\title{
The Effects of International Shocks on Australia's Business Cycle*
}

\author{
PHILIP LIU \\ Centre for Applied Macroeconomics Analysis, The Australian National University, Canberra, ACT, \\ Australia
}

\begin{abstract}
This article examines the sources of Australia's business cycle fluctuations. The cyclical component of gross domestic product is extracted using the Beveridge-Nelson decomposition and a structural Vector autoregressive model (VAR) model is identified using robust sign restrictions derived from a structural small open economy model. In contrast to previous VAR studies, international factors are found to contribute to over half of the output forecast errors whereas demand shocks have relatively modest effects.
\end{abstract}

\section{Introduction}

There is little consensus on the role played by the rest of the world in a small open economy's business cycle. In the case of Australia, Dungey (2002) estimates a structural vector autoregression (SVAR) model, which implies that international factors account for 32 per cent of output forecast errors over a 1-year horizon, whereas gross domestic product (GDP) shocks remain the dominant contributor. An SVAR model for Australia by Brischetto and Voss (1999) reveals that only around 5 per cent of output forecast

* The author thanks Farshid Vahid, Jarkko Jaaskela, Kristoffer Nimark, Renee Fry, Chris Kent, David Vines, Heather Anderson, Warwick McKibbin and two anonymous referees for helpful comments and insightful discussions, and seminar participants at the University of Otago and ANU. The author's research has benefitted from support provided by ARC grant DP0664024.

JEL classifications: E32, E52, E63, F41

Correspondence: Philip Liu, Centre for Applied Macroeconomics Analysis, College of Business \& Economics, Arndt Building (24), The Australian National University, Canberra, ACT 0200, Australia. Email: pliu@imf.org errors stems from foreign factors. However, using an estimated New Keynesian dynamic stochastic general equilibrium (DSGE) model, Nimark (2007) concludes foreign shocks explain over 50 per cent of the variance in Australian output around its trend whereas domestic output shocks account for only 8 per cent. Using a different criteria, Dungey and Pagan (2000) simulate data from a SVAR model and find that recessions would have been less severe in the absence of foreign disturbances, whereas cumulated movements during the expansion phrase would also have been smaller.

This article argues that the different findings of the studies cited before can be understood as resulting from the difficulty of deciding how to appropriately identify the structural disturbances relevant to a small open economy. Identifying restrictions for SVAR models may introduce substantial mis-specifications that could lead to invalid inference. At the same time, identification of structural disturbances by means of cross-equation restrictions from a small DSGE model may be too stringent a method to capture the complex dynamics of the data-generating process. This article contributes to this debate by developing a VAR model of 
the Australian economy using robust sign restrictions derived from an estimated DSGE model. One key element of this approach is that it allows for a theoretically consistent view of the relationships between the set of macro variables without imposing the full DSGE structure.

Earlier sign restriction VAR studies focus mainly on identifying a subset of structural disturbances. Examples include: Faust (1998) and Uhlig (2005) who identify only monetary policy shocks. More recent studies by Canova and De Nicolo (2002) and Peersman (2005) apply the sign restriction methodology to identify all shocks in the VAR model. All these studies, however, are based on large economies with little discussion of the role of exchange rates. One exception is Farrant and Peersman (2006), who investigate the role of exchange rates in an open economy setting. However, the role of international factors is not explicitly discussed in that study.

The use of restrictions derived from a theoretical model to aid VAR estimation is not new. Mckibbin et al. (1998) use the McKibbin-Sachs Global (MSG2) model to restrict the long-run behaviour of a VAR, whereas the short-run features are left unrestricted. Dungey and Pagan (2009) try to reconcile their earlier SVAR model with restrictions implied by a simple open economy DSGE model. Peersman and Straub (2004) use a calibrated real business cycle model to derive sign restrictions to identify technology shocks.

The starting point of this article is to use the Beveridge-Nelson (BN) decomposition to extract the cyclical component of GDP, which will be used as a measure of Australia's business cycle. A slightly modified version of the small open economy model, proposed in both Monacelli (2005) and Gali and Monacelli (2005), is then estimated using maximum likelihood. The estimated model is used to determine a set of robust sign restrictions for the VAR analysis. The small open economy assumption is imposed on the VAR model by restricting the impact of domestic variables on foreign variables. The ultimate aim of the analysis is to map the set of statistical relationships estimated from the reduced form VAR back into a set of structural disturbances for economic interpretation. To do this, an algorithm similar to that proposed by Canova and De Nicolo (2002) is used to trace out all possible orthogonal vector moving average (VMA) representations of the VAR that are consistent with the sign restrictions derived from the estimated DSGE model.

As there is not enough information to uniquely identify a set of structural disturbances, the median impulse approach suggested in Fry and Pagan (2005) is used to summarise the results.

The analysis reveals several interesting results. First, the $\mathrm{BN}$ decomposition produces a plausible measure of Australia's output fluctuations. The characteristics of the cyclical behaviour match previous business cycle studies using factor models such as Gillitzer et al. (2005). Second, in contrast to previous SVAR studies for Australia, foreign factors account for over half of the output forecast errors whereas innovations from output itself have only a modest effect. The result is robust across different foreign specifications using data for the United States and the Group of Seven (G7) countries.

The rest of the article is organised as follows. Section II describes the BN decomposition used to extract the cyclical component of GDP. Section III outlines the estimated small open economy DSGE model together with the data used in the analysis. A set of robust sign restrictions is derived from the estimated DSGE model for the open economy VAR. Section IV describes the estimation and identification of the open economy sign restriction VAR model. Section V summarises the estimation results. Finally, Section VI reviews the main findings.

\section{The Cyclical Component of GDP}

The first step of the analysis of this article is to obtain a measure of the cyclical component of GDP. The cyclical component is defined as the difference between the actual and permanent components of GDP. ${ }^{1}$ The permanent component is exctracted by means of a $\mathrm{BN}$ decomposition, which is preferred to one popular alternative, the Hodrick-Prescott (HP) filter as the BN decomposition allows for correlation between the innovations to the permanent and cyclical components.

\footnotetext{
${ }^{1}$ The terms 'permanent component' and 'trend' are used interchangeably, as are 'cyclical component' and 'the cycle'. A detailed review of various detrending methods can be found in Canova (1998).
} 
TABLE 1

Test Results: Akaike Information Criteria (AIC), Bayesian Information Criteria (BIC) and $R^{2}$

\begin{tabular}{|c|c|c|c|c|}
\hline Model & Parameter estimates & AIC & $\mathrm{BIC}$ & $R^{2}$ \\
\hline $\operatorname{ARIMA}(1,1,1)$ & $c_{t}=0.14 c_{t-1}+0.17 \epsilon_{t-1}+\epsilon_{t}$ & -6.828 & -6.752 & 0.098 \\
\hline $\operatorname{ARIMA}(2,1,0)$ & $c_{t}=0.30 c_{t-1}+0.01 c_{t-2}+\epsilon_{t}$ & -6.870 & -6.769 & 0.094 \\
\hline $\operatorname{ARIMA}(2,1,1)$ & $c_{t}=-0.62 c_{t-1}+0.24 c_{t-2}+0.64 \epsilon_{t-1}+\epsilon_{t}$ & -6.825 & -6.728 & 0.151 \\
\hline $\operatorname{ARIMA}(2,1,2)$ & $c_{t}=-0.35 c_{t-1}+0.42 c_{t-2}+0.72 \epsilon_{t-1}-0.27 \epsilon_{t-1}+\epsilon_{t}$ & -6.854 & -6.749 & 0.154 \\
\hline
\end{tabular}

A time series $y_{t}$ with an $\operatorname{ARIMA}(p, 1, q)$ representation can be decomposed into a permanent $\left(\tau_{t}\right)$ and a cyclical $\left(c_{t}\right)$ component using the $\mathrm{BN}$ decomposition as follows:

$$
y_{t}=\tau_{t}+c_{t},
$$

where $\tau_{t}=\mu+\tau_{t-1}+\alpha \epsilon_{t}$ is the unobserved permanent component, which is assumed to follow a random walk with an average growth rate of $\mu$; and $c_{t}=\phi_{p}(L) c_{t}+\psi_{q}(L) \epsilon_{t}+(1-\alpha) \epsilon_{t}$ is a stationary and invertible $\operatorname{ARMA}(p, q)$ process, where $\phi_{p}(0)=0$ and $\Psi_{q}(L)=0$.

Both the Akaike information (AIC) and Schwarz criteria suggest that an $\operatorname{ARIMA}(2,1,1)$ model provides the best empirical fit for Australian quarterly real GDP between 1980Q4 and 2006Q1. The BN decomposition is computed based on the method suggested by Newbold (1990). The results for four alternative models are summarised in Table 1. Figure 1 shows that the $\mathrm{BN}$ cycle is more volatile than the cycle derived using the HP filter (based on the smoothing parameter $\lambda=1600)$. This is particularly so in the first half of the sample ${ }^{2}$ which displays more pronounced cycles. The two cycles have a similar peak frequency (estimated using the periodogram) around 17 quarters over the sample, with the $\mathrm{BN}$ cycle containing noticeably more high frequency oscillations. Figure 1 also shows the coincident (GKR) index of Australian economic activity derived by Gillitzer et al. (2005) using a factor model. This index provides a plausible measure of the Australian business cycle using a large number of macroeconomic variables.

The three series each imply a different underlying model. The aim here is to compare

\footnotetext{
2 The standard deviation of the BN cycle is 3.9 per cent compared with 1.4 per cent for the HP cycle over the whole sample.
}

and contrast the different cyclical behaviour across the three detrending assumptions rather than to judge which is the best method to use. ${ }^{3}$ For all three series, the two recessions during the early 1980s and 1990s are apparent. The BN cycle and GKR index coincide with respect to the timing of recessions, suggesting a bottoming out of economic activity around 1983Q1 and 1991Q1. The HP cycle is a bit slower at picking up the recessions. ${ }^{4}$ In addition, the BN cycle identifies two episodes of weak economic activity over the sample period. The first was a sharp depreciation of the exchange rate and a downturn in household expenditure, in 1986, which coincides with Paul Keating's Banana Republic remark over concerns about Australia's foreign debt position. The slowdown of the economy following the end of the Sydney Olympic games and the introduction of the goods and services tax in 2000 is also apparent.

\section{A Stylised Small Open Economy DSGE Model}

This section presents the estimated small open economy DSGE model. The model is based on a slightly modified version of that proposed by Monacelli (2005) and Gali and Monacelli (2005). The key advantage of using this model is because of its simplicity and the model includes the set of variables that are crucial for small open economy studies. It also embeds the key theoretical linkages often found in larger small open economy DSGE models. Variants of

\footnotetext{
${ }^{3}$ Another approach is to explicitly estimate the permanent component using a structural vector error correction model as in Pagan and Pesaran (2008).

${ }^{4}$ The HP filter can be thought of as a two-step filter: in the first step, it renders $y_{t}$ stationary; in the second, it smooths the resulting stationary series with asymmetric MA weights, which can contribute to a delay in identifying the recessions.
} 
FiguRE 1

Cycles in Australian Gross Domestic Product

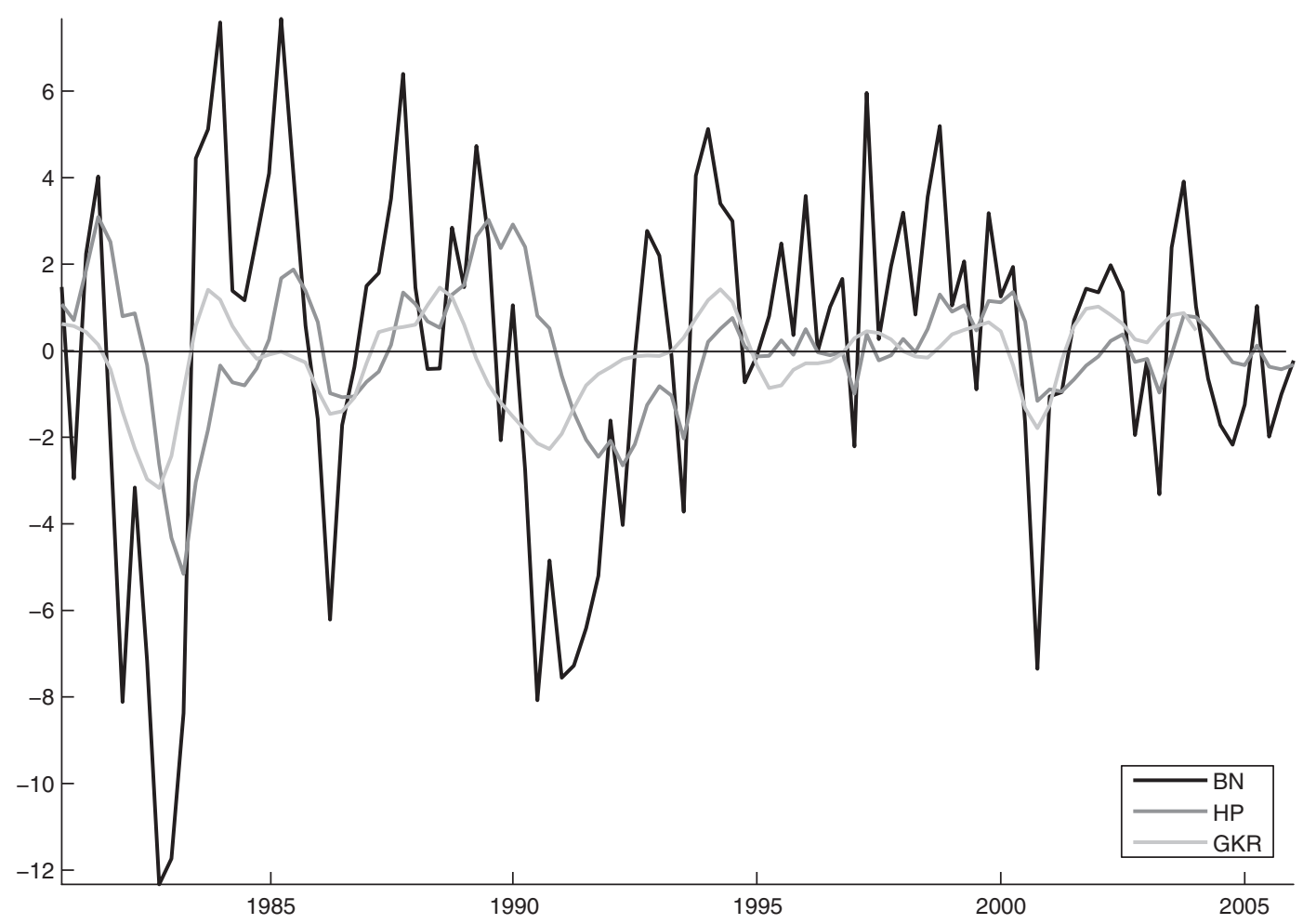

Note: GKR is the cycle derived by Gillitzer, Kearns and Richards (2005) using a factor model.

the proposed model have been heavily used in other applied macroeconomic research. Recent examples include Lubik and Schorfheide (2006) looking at the role of the exchange rate in the central bank's reaction function, and Dungey and Pagan (2009) compare the model structure with their earlier SVAR model (see Dungey and Pagan, 2000).

Del Negro and Schorfheide (2009) argue model mis-specification, in a sense that the model imposes invalid restrictions on the MA representation of the macroeconomic time series, remains the key challenge for using DSGE models in empirical policy studies. Although the specific quantitative predictions of DSGE models may be questionable, the theoretical linkages embedded in DSGE model remains useful for the understanding of contemporaneous relationships among key macroeconomic variables. This is the key motivation for using some but not all of the DSGE model's predictions in the form of robust sign restrictions. The estimated model is simulated to provide these set of restrictions for the VAR analysis.

The model consists of an open economy investment and saving equilibrium (IS) equation and a Phillips curve incorporating imperfect exchange rate pass-through. The monetary authority sets interest rates according to a Taylor-type reaction function, whereas the exchange rate depends on the interest rate differential between the domestic and foreign economies. The variables for the rest of the world are taken to be exogenous processes. The open economy IS equation derived from the consumer's optimising problem is: 


$$
\begin{aligned}
y_{t}= & n_{1} y_{t-1}+\left(1-n_{1}\right) E_{t} y_{t+1}-n_{2}\left(r_{t}-E_{t} \pi_{t+1}\right) \\
& +n_{3} E_{t} \Delta y_{t+1}^{*}-n_{4} z_{t}+n_{5} E_{t} \Delta \psi_{t+1},
\end{aligned}
$$

where $n_{1}, \ldots, n_{5}$ are parameters; ${ }^{5} y_{t}$ is the aggregate output gap; $r_{t}$ is the nominal interest rate; $\pi_{t}$ is the inflation rate; $y_{t}^{*}$ is the foreign output gap; and $z_{t}$ represents technology disturbances that follow an $\operatorname{AR}(1)$ process. ${ }^{6} \psi_{t}=$ $(1-\gamma) s_{t}-q_{t}$ can be interpreted as the law of one price gap which measures the deviation of the domestic price of imported goods from the world price, where $s_{t}$ is the terms of trade, defined as export prices relative to import price, and $q_{t}$ is the real exchange rate. A non-zero $\psi_{t}$ implies imperfect exchange rate pass-through to import prices. The backward looking component, $y_{t-1}$, in the IS equation is motivated by the assumption of habit persistence in consumer preferences.

The open economy New Keynesian Phillips Curve derived by solving the firm's pricing decision can be written as:

$$
\pi_{t}=g_{1} \pi_{t-1}+\left(1-g_{1}\right) E_{t} \pi_{t+1}+g_{2} y_{t}+g_{3} \psi_{t}+\epsilon_{\pi, t},
$$

where $\epsilon_{\pi, t}$ represents a cost push shock. The Phillips curve is based on the assumption of monopolistically competitive firms, subject to pricing constraints (Calvo pricing and indexation). If $g_{3}=0$, Equation (3) collapses down to a familiar closed economy Phillips curve where inflation dynamics are partly driven by past and expected inflation, in addition to the output gap. The open economy dimension includes the effects from the exchange rate as an important part of the monetary policy transmission process.

The assumption of perfect capital markets yields the standard uncovered interest parity (UIP) condition (which links the expected

\footnotetext{
${ }^{5}$ It is important to note that without further restrictions, it is not possible to separately identify the parameter $\eta_{4}$ and the variance of the unobserved stochastic shock $z_{t}$. At a conceptual level, this does not cause real difficulty in the estimation procedure employed here (based on Monte Carlo Markov Chain simulations rather than numerical optimisation); see An and Schorfheide (2007). However, it is important to keep in mind that these two parameters have limited structural meaning. Nevertheless, this will not affect the sign restrictions used for the VAR model.

${ }^{6}$ A positive innovation to technology will increase the potential output of the economy and hence has a negative effect on the output gap.
}

exchange rate depreciation to the interest rate differential):

$$
q_{t}=E_{t} q_{t+1}+\left(r_{t}-E_{t} \pi_{t+1}\right)-\left(r_{t}^{*}-E_{t} \pi_{t+1}^{*}\right)+U_{q, t},
$$

where $U_{q, t}$ is a time-varying risk premium that follows an $\mathrm{AR}(1)$ process.

The monetary authority is assumed to set the nominal interest rate according to a Taylor rule based on contemporaneous inflation and output as well as an interest rate smoothing term:

$$
r_{t}=\rho_{r} r_{t-1}+\left(1-\rho_{r}\right)\left[\phi_{1} \pi_{t}+\phi_{2} y_{t}\right]+\epsilon_{r, t},
$$

where $\epsilon_{r, t}$ represents a non-systematic deviation from the reaction function. To complete the description of the structural model, the terms of trade $s_{t}$, the foreign output gap $y_{t}^{*}$, foreign interest rates $r_{t}^{*}$ and foreign inflation $\pi_{t}^{*}$ are assumed to follow exogenous AR(1) processes.

The structural model can be summarised as:

$$
A_{0} Y_{t}=A_{1} Y_{t-1}+A_{2} E_{t} Y_{t+1}+\epsilon_{t},
$$

where $Y_{t}=\left[y_{t}, r_{t}, \pi_{t}, q_{t}, s_{t}, r_{t}^{*}, y_{t}^{*}, \pi_{t}^{*}, \psi_{t}, z_{t}, U_{q, t}\right]$ is a $11 \times 1$ vector containing the state variables of model and $\epsilon_{t}=\left[\epsilon_{z, t}, \epsilon_{r, t}, \epsilon_{\pi, t}, \epsilon_{q, t}, \epsilon_{s, t}, \epsilon_{r^{*},}, t, \epsilon_{y^{*}}, t, \epsilon_{\pi^{*}}, t\right]$ is an $8 \times 1$ vector of structural innovations. ${ }^{7}$ The solution of the model can be represented as a first-order VAR:

$$
Y_{t}=B_{1} Y_{t-1}+B_{2} \epsilon_{t}
$$

\section{(i) Data Description}

Data from 1980Q1 to 2006Q1 for the Australian economy is used to estimate the structural model and the VAR. ${ }^{8}$ The starting period coincides with previous SVAR studies of the Australian economy including Dungey and Pagan (2000). Quarterly observations on real total GDP $\left(y_{t}\right)$, quarterly headline consumer price index (CPI) inflation (excluding interest rates and taxes; $\pi_{t}$ ), the (goods and services) terms of trade $\left(s_{t}\right)$, the real exchange rate $\left(q_{t}\right)$, the nominal interest rate (measured by the 90-day bank bill rate; $\left.r_{t}\right)$; US GDP $\left(y_{t}^{*}\right)$, US CPI inflation quarter-on-quarter $\left(\pi_{t}^{*}\right)$ and US nominal interest rate $\left(r_{t}^{*}\right)$ are sourced from the Reserve Bank of

\footnotetext{
${ }^{7}$ In the numerical simulation and estimation of the model, the structural equation is solved using a solution algorithm described in Uhlig (1995).

${ }^{8}$ The effective sample period is from 1980Q4 to 2006Q1 after differencing and construction of the cyclical component of GDP.
} 
Australia (RBA), the Australian Bureau of Statistics and the IMF's International Financial Statistics database. ${ }^{9}$

The cyclical component of GDP for both Australia and the United States - that is, the output gap measures - are constructed using the BN decomposition described earlier. As a result of the unusual upswing in Australia's terms of trade between 2004 and 2006, this time series is detrended using an HP filter to ensure stationarity of the series. ${ }^{10}$ All variables apart from inflation and interest rates enter in logs.

\section{(ii) Estimating the DSGE Model}

The parameters of the DSGE model are estimated using constrained maximum likelihood (ML). The likelihood function is computed via the state-space representation of the model's solution in Equation (7), together with the measurement equation linking the observed data and the state vector:

$$
Z_{t}=G Y_{t},
$$

where $Z_{t}$ denotes the observed data; and the matrix $G$ specifies the relationship between the state variables and the observed data. The posterior parameter distribution is simulated using the Metropolis Hasting (MH) algorithm described in Lubik and Schorfheide (2007).

The ML estimates are generated conditional on the ordinary least square (OLS) estimate of the model's four exogenous processes that explain developments in the rest of the world: the terms of trade $s_{t}$, foreign inflation $\pi_{t}^{*}$, interest rates $r_{t}^{*}$ and output $y_{t}^{*}$. There are two advantages in estimating the observed exogenous processes independently of the model. First, it reduces the number of parameters to be estimated in the simulation algorithm. Second, Fukac and Pagan (2006) argue that rigid restrictions imposed by DSGE models on the data may

\footnotetext{
${ }^{9}$ Data for the G7 economies is also taken from the IMF's IFS and combined using the following weights: the United States (0.49), Japan (0.16), Germany (0.10), the United Kingdom (0.07), France (0.07), Italy (0.07) and Canada (0.04).

${ }^{10}$ The HP filter imposes the requirement that the permanent component of the ToT series is an I(2) process, that is, the ToT series is subject to shifts in the trend growth rate. The HP filter was used as a simplistic assumption and close examination does reveal a small albeit insignificant upward trend in the growth rate of the ToT.
}

yield invalid estimates of the model's observable shocks (i.e. shocks that are mapped into actual data, such as the foreign output gap $y_{t}^{*}$ ).

The ML estimate of the model's parameters from the 1.5-million Markov chain draws are summarised in Table 2. ${ }^{11}$ The set of Markov chain diagnostic tests imply that the simulated chains attain their stationary distributions. ${ }^{12}$ The degree of backward lookingness is estimated to be 0.09 for the IS equation $\left(n_{1}\right)$ and 0.27 for the Phillips curve $\left(g_{1}\right)$. The estimated coefficient on the real interest rate $\left(n_{2}\right)$ in the IS equation is relatively small suggesting output variation is relatively insensitive to interest rate changes. The response of inflation to output gap changes $\left(g_{2}\right)$ is also estimated to be low. The Taylor rule displays a significant degree of interest rate smoothing behaviour with $\rho_{r}$ estimated to be 0.90 . The estimated weight on output is slightly higher than that on inflation and consistent with standard calibrated values used in the literature. However, the estimation covers a period before the inflation targeting regime; it is no surprise that there is a wide confidence interval around the Taylor rule coefficient on output, $\phi_{2}$.

\section{(iii) Qualitative Analysis of the DSGE Model's} Impulse Response Functions

This section presents is the impulse response functions (IRFs) of the model. The IRFs are simulated by sampling the empirical distribution of the estimates of the DSGE model. This takes into account the uncertainty of the responses associated with parameter uncertainty. The median (solid lines) along with the 5th and 95th percentile (dotted lines) responses are shown in Figures 2 and 3. The IRFs of the model are broadly consistent with other open economy studies based on New Keynesian models. Moreover, the initial responses of key variables are generally quantitatively significant providing a useful set of robust sign restrictions for the VAR analysis. The discussion here will focus more on the initial responses rather than the dynamic adjustments to the shocks.

\footnotetext{
${ }^{11}$ A 50 per cent burn-in is discarded before computing the summary statistics.

12 There is only one exception, $n_{4}$, which is significant at the 5 per cent level. However, a small Brooks and Gelman (1998) statistic of 1.12 indicates that the chain has converged.
} 
TABLE 2

Maximum Likelihood Estimates of the Structural Model

\begin{tabular}{|c|c|c|c|c|c|c|c|}
\hline \multirow[b]{2}{*}{ Parameters } & \multicolumn{4}{|c|}{ MLE statistics (MLE) } & \multicolumn{3}{|c|}{ Diagnostics } \\
\hline & Mean & SD & $2.5 \%$ & $97.5 \%$ & NSE & $P$-value & BG \\
\hline$n 1$ & 0.09 & 0.06 & 0.01 & 0.24 & 0.00 & 0.06 & 1.03 \\
\hline$n 2$ & 0.01 & 0.01 & 0.00 & 0.04 & 0.00 & 0.75 & 1.00 \\
\hline$n 3$ & 0.21 & 0.10 & 0.05 & 0.43 & 0.01 & 0.54 & 1.01 \\
\hline$n 4$ & 0.26 & 0.09 & 0.15 & 0.50 & 0.01 & 0.02 & 1.12 \\
\hline$n 5$ & -0.70 & 0.16 & -1.11 & -0.43 & 0.02 & 0.56 & 1.01 \\
\hline$g 1$ & 0.27 & 0.05 & 0.16 & 0.37 & 0.01 & 0.93 & 1.00 \\
\hline$g 2$ & 0.01 & 0.01 & 0.00 & 0.04 & 0.00 & 0.09 & 1.01 \\
\hline$g 3$ & 0.00 & 0.00 & 0.00 & 0.01 & 0.00 & 0.24 & 1.00 \\
\hline$\rho_{r}$ & 0.90 & 0.02 & 0.84 & 0.93 & 0.00 & 0.07 & 1.11 \\
\hline$\phi_{1}$ & 1.31 & 0.22 & 1.02 & 1.87 & 0.03 & 0.24 & 1.05 \\
\hline$\phi_{2}$ & 1.56 & 0.38 & 0.78 & 2.30 & 0.05 & 0.16 & 1.09 \\
\hline$\rho_{z}$ & 0.78 & 0.07 & 0.62 & 0.89 & 0.01 & 0.22 & 1.04 \\
\hline$\rho_{u}$ & 0.98 & 0.01 & 0.95 & 1.00 & 0.00 & 0.94 & 1.00 \\
\hline$\sigma_{z}$ & 2.10 & 0.16 & 1.83 & 2.52 & 0.02 & 0.95 & 1.00 \\
\hline$\sigma_{\pi}$ & 1.03 & 0.22 & 0.72 & 1.54 & 0.03 & 0.36 & 1.03 \\
\hline$\sigma_{r}$ & 1.10 & 0.08 & 0.97 & 1.28 & 0.01 & 0.92 & 1.00 \\
\hline$\sigma_{q}$ & 1.78 & 0.13 & 1.55 & 2.06 & 0.02 & 0.13 & 1.05 \\
\hline$\rho_{s}$ & OLS & 0.90 & & & & & \\
\hline$\rho_{r^{*}}$ & OLS & 0.94 & & & & & \\
\hline$\rho_{\pi^{*}}$ & OLS & 0.62 & & & & & \\
\hline$\rho_{y^{*}}$ & OLS & 0.29 & & & & & \\
\hline$\sigma_{s}$ & OLS & 1.75 & & & & & \\
\hline$\sigma_{r^{*}}$ & OLS & 1.07 & & & & & \\
\hline$\sigma_{\pi^{*}}$ & OLS & 1.67 & & & & & \\
\hline$\sigma_{y^{*}}$ & OLS & 4.14 & & & & & \\
\hline
\end{tabular}

Notes: The posterior statistics are computed based on 1 million Markov Chains Monte Carlo (MCMC) draws after a 50 per cent burn in period. NSE refers to the numerical standard error of the Markov chain. P-value relates to the test of two means between the first and second halves of the stationary Markov chain. BG refers to the Brooks and Gelman (1998) univariate shrink factor. A shrink factor close to 1 is an indication of attaining a stationary distribution. OLS indicates Ordinary least square.

A positive technology shock will increase the potential output of the economy ( $\tau_{t}$ in Eqn 1), because of nominal rigidities, actual output that will take time to adjust to the new higher potential level of output; thus, the output gap falls. This causes the interest rate to fall. The real exchange rate depreciates to reflect the change in the interest rate differential, which contributes to a small increase in the inflation rate, despite the boost to productivity.

A cost push shock increases inflation, and leads to an increase in interest rates that causes the exchange rate to appreciate and output to contract.

A negative shock to the risk premium causes lower inflation and output, owing to an appreciating exchange rate. The central bank responds by reducing the interest rate. An unexpected tightening of monetary policy has a negative effect on the output gap, with lower inflation and an appreciated exchange rate.

Turning to external factors, following a positive shock to Australia's terms of trade, the output gap increases, the real exchange rate appreciates and inflation and interest rates rise. An exogenous increase in the foreign interest rate leads to a depreciation of the domestic currency, which is sufficient to raise the output gap and together these forces push up inflation. Given the simple structure of the model, an increase in foreign inflation has a similar but opposite effect on the domestic economy as increases in the foreign nominal interest rate. An increase in foreign output actually decreases the domestic output gap, whereas both domestic inflation and interest rates stay relatively static and the depreciating exchange rate helps 
FIGURE 2

Structural Model Impulse Response Functions of Technology, Monetary Policy, Cost Push, Risk Premium Shock
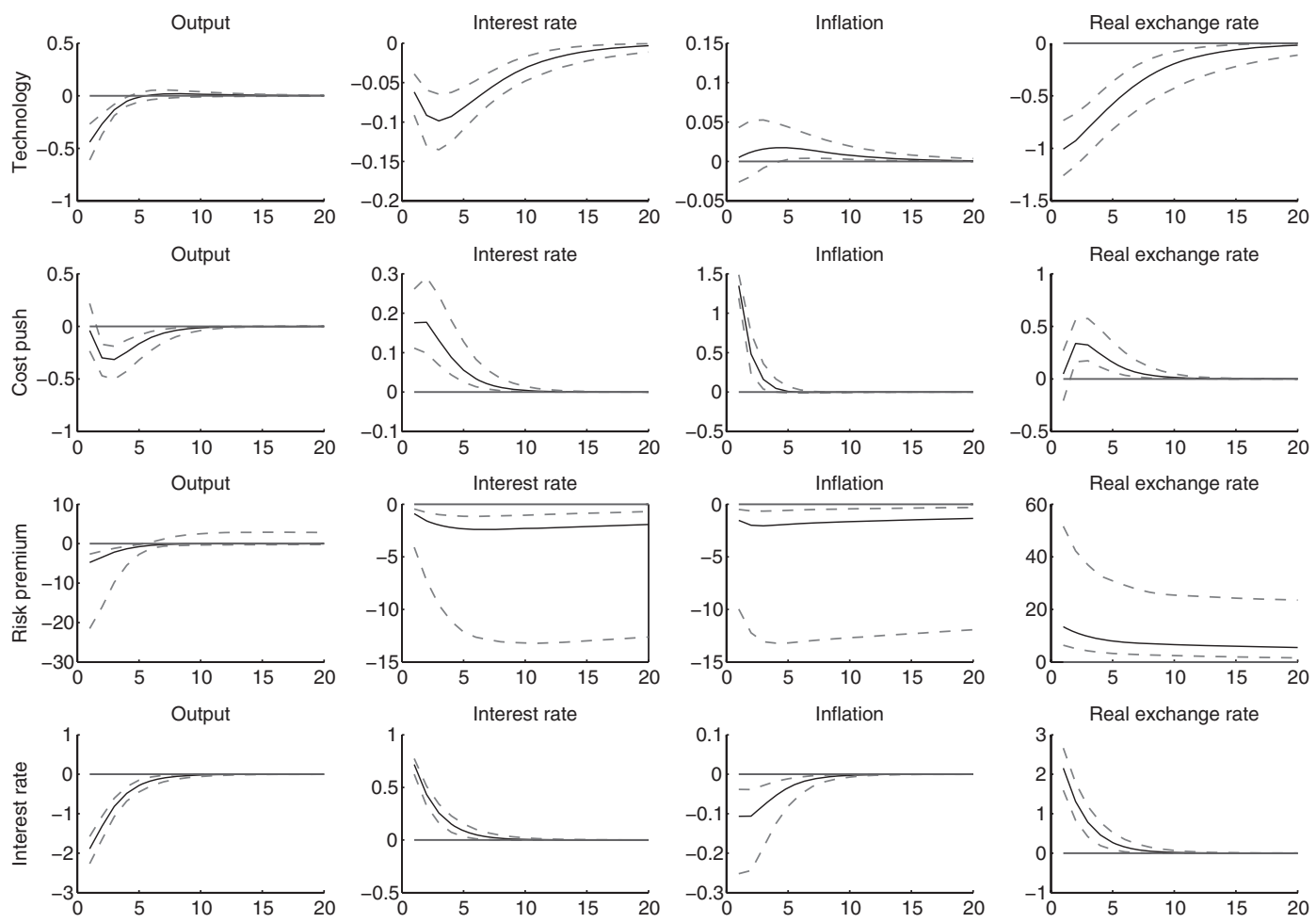

balance the international consumption risk-sharing condition. ${ }^{13}$

\section{(iv) Robust Sign Restrictions}

The focus of the study is to gather a set of sign restrictions from the impulse responses of the DSGE model to identify the structural shocks of a small open economy VAR. The complete set of estimated IRFs from the DSGE model provides more sign restrictions than are necessary to disentangle the eight structural shocks. Bearing in mind the potential mis-specification issue, not all the restrictions from the model are imposed upon the VAR. One can think of the set of sign restrictions imposed in the article as the minimum set of restrictions needed to disentangle the eight shocks. The

${ }^{13}$ Gali and Monacelli (2005) provide a detailed account of the way in which such a shock can lower domestic potential output.

chosen set of sign restrictions is broadly consistent with restrictions implied by other standard open economy structural models. ${ }^{14}$ The set of sign restrictions adopted are presented in Table 3.

There are a few important things worth highlighting. First, given that the three foreign variables enter the structural model as exogenous driving processes, the set of sign restrictions imposed on the foreign economy follows the dynamic responses implied by a canonical closed economy New Keynesian model. The responses of the domestic variables to the three

${ }^{14}$ Additional and/or alternative choices can potentially give different IRFs for the VAR, in particular the response to domestic shocks. However, the results of international shocks (the key focus of the article) should remain fairly robust because there are no explicit restrictions imposed on the domestic economy from international shocks. 
FIGURE 3

Structural Model Impulse Response Function of Terms of Trade (ToT), Foreign Interest, Inflation and Output Shock
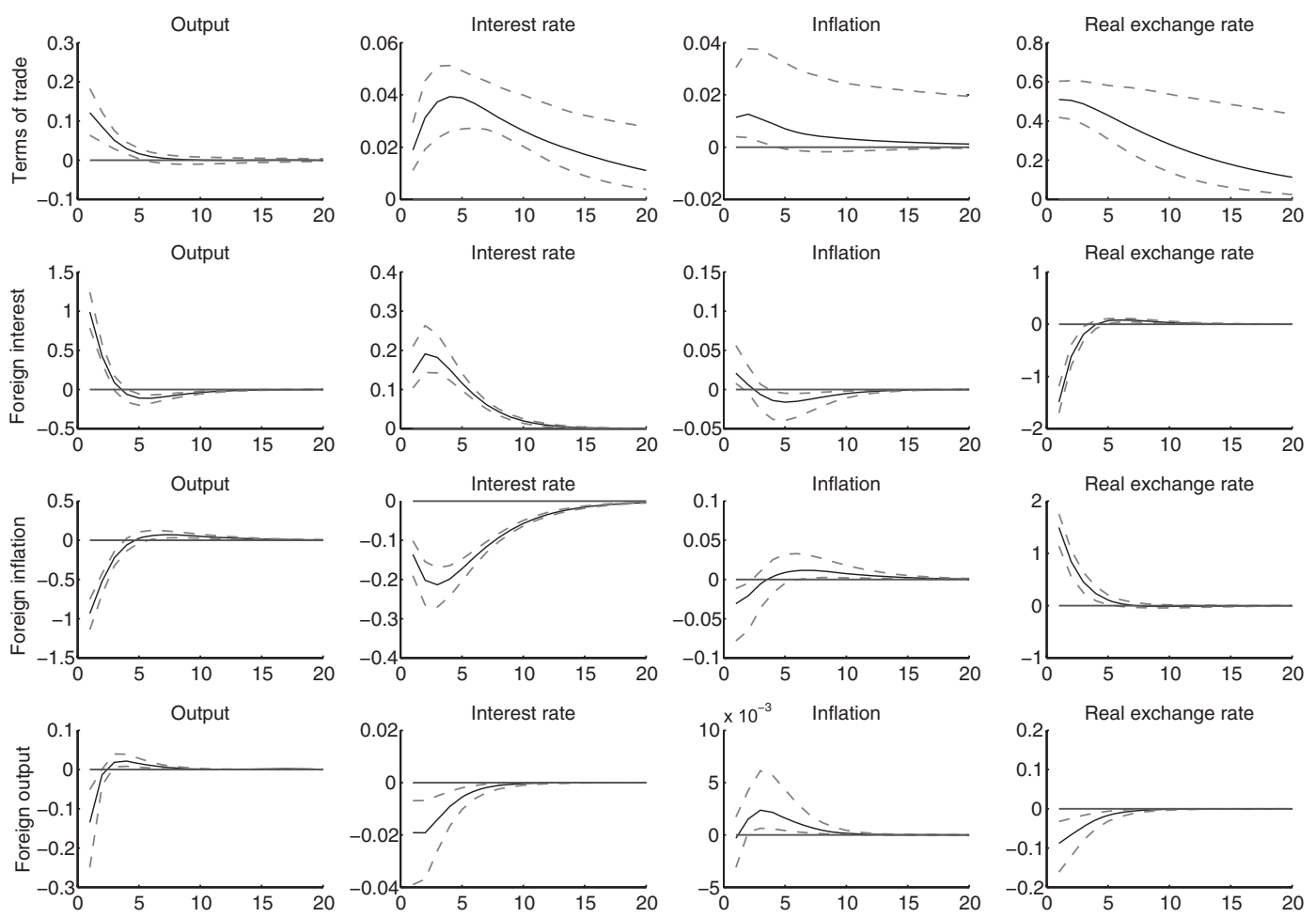

foreign shocks are left unrestricted. Second, the terms of trade is treated as an endogenous variable and its response to other shocks apart from the output shock are also left unrestricted. ${ }^{15}$ With the presence of sticky home prices in the short run, the terms of trade responds to other variables in the system via changes to domestic inflation. Third, the output shock can be viewed as anything that moves output and interest rates together but is orthogonal to all other shocks in the system. Finally, the sign restrictions are imposed for the initial two quarters only.

\section{Estimating a VAR Model}

This section sets out the small open economy sign-restricted VAR model estimated using the data described in Section IV(i). An eightvariable VAR(2) is fitted to quarterly observa-

\footnotetext{
15 The terms of trade is defined here as the domestic currency relative price of exports over imports.
}

tions from 1980Q4 to 2006Q1 where the number of lags are determined by the AIC.

Consider a general $\operatorname{VAR}(p)$ model with $n$ variables $Y_{t}$ :

$$
B Y_{t}=A(L) Y_{t-1}+\epsilon_{t},
$$

where $A(L)=A_{1} L+\cdots+A_{p} L^{p}$ is an $p$ th order matrix polynomial; $B$ is an $(n \times n)$ matrix of coefficients that reflect the contemporaneous relationships among $Y_{t}$; and $\epsilon_{t}$ is a set of $(n \times T)$ normally distributed structural disturbances with mean zero; and variance covariance matrix $\Sigma$, $\Sigma_{i, j}=0 \forall i \neq j$. The structural representation in Equation (9) has the following reduced form:

$$
Y_{t}=\Pi(L) Y_{t-1}+e_{t},
$$

where $\Pi(L)=B^{-1} A(L)$ and $e_{t}$ is a set of $(n \times T)$ normally distributed reduced-form errors with mean zero and variance covariance matrix $V$, $V_{i, j} \neq 0 \forall i, j$. The aim is to map the statistical relationships summarised by the reduced form 
TABLE 3

VAR Sign Restrictions

\begin{tabular}{lcccccccc}
\hline & $r^{*}$ & $y^{*}$ & $\pi^{*}$ & $y$ & $r$ & $\pi$ & $q$ & $s$ \\
\hline Foreign interest & $\uparrow$ & - & $\downarrow$ & - & - & - & - & - \\
Foreign output & $\uparrow$ & $\uparrow$ & - & - & - & - & - & - \\
Foreign inflation & $\uparrow$ & $\downarrow$ & $\uparrow$ & - & - & - & - & - \\
Output (composite) & 0 & 0 & 0 & $\uparrow$ & $\uparrow$ & - & - & - \\
Monetary policy & 0 & 0 & 0 & - & $\uparrow$ & $\downarrow$ & - & - \\
Cost push & 0 & 0 & 0 & $\downarrow$ & $\uparrow$ & $\uparrow$ & $\uparrow$ & - \\
Risk premium & 0 & 0 & 0 & - & - & $\uparrow$ & $\uparrow$ & $\uparrow$ \\
Terms of trade & 0 & 0 & 0 & - & $\uparrow$ & $\uparrow$ & & \\
\hline
\end{tabular}

errors $e_{t}$ back into economic relationships described by $\epsilon_{t}$. Let $P=B^{-1}$. The reduced form errors are related to the structural disturbances in the following manner:

$$
e_{t}=P \epsilon_{t} \quad \text { and } \quad V=E\left(e_{t} e_{t}^{\prime}\right)=H H^{\prime},
$$

for some matrix $H$ such that $H H^{\prime}=P \Sigma P^{\prime}$. An identification problem arises if there are not enough restrictions to uniquely pin down $H$ from the matrix $V .^{16}$

\section{(i) Identification Through Sign Restrictions}

The identification of structural shocks is often a controversial issue, with different identifying assumptions leading to quite different conclusions. Typical restrictions employed in the literature are based on restricting the short or long-run impact of certain shocks on a subset of variables to be zero. The Choleski decomposition is an example of one such strategy where the contemporaneous impact of shocks follows a recursive ordering. One noticeable feature of standard empirical DSGE models is that they almost never imply zero contemporaneous impacts. This is also the case with the estimated structural model presented in Section III.

The central idea behind SVAR analysis is to decompose the set of reduced form shocks, characterised by $V$, into a set of orthogonal structural disturbances characterised by $\Sigma$. However, there are an infinite number of ways in which this orthogonality condition can be achieved. Let $H$ be an orthogonal decomposition of $V=$ $H H^{\prime}$. The multiplicity arises from the fact that

\footnotetext{
16 There are $n^{2}$ unknown elements in $H$ with only $n(n+1) / 2$ unique elements in $V$.
}

for any orthonormal matrix $Q$ (where $Q Q^{\prime}=I$ ), such that $V=H Q Q^{\prime} H^{\prime}=\tilde{H} \tilde{H}^{\prime}$ is also an admissible decomposition of $V$. This decomposition does not have any economic content, but nevertheless, produces a set of uncorrelated shocks $\epsilon_{t}=\tilde{H} e_{t}$, without imposing any zero contemporaneous restrictions.

The identification strategy used here closely follows Canova and De Nicolo (2002), Uhlig (2005) and Peersman (2005) in using qualitative information directly from IRFs to achieve identification. Canova and De Nicolo (2002) proposed an algorithm to trace out all possible orthogonal VMA representations of the VAR consistent with a given set of sign restrictions. See the Appendix for a more detailed description of the algorithm.

\section{(ii) Finding the Median Impulse}

The next step is to construct a summary measure from all the VAR representations consistent with the given set of sign restrictions. A common approach is to examine all of the feasible IRFs implied, and report the median response at each horizon for each variable. However, Fry and Pagan (2005) criticise this approach as the implied 'median' IRF may not actually be a feasible response (as it is likely to consist of selected parts of paths implied by different candidate functions). In other words, inference is difficult because the orthogonality condition may be violated.

Fry and Pagan suggest locating a unique identification matrix such that all the feasible impulses are closest to its median while maintaining the orthogonality condition. Each feasible VAR representation can be distinguished by the rotation angle, $\theta$. So the objective is to choose $\theta$ so as to minimise: 


$$
\Upsilon\left(\theta_{j}\right)=\sum_{i=1}^{q}\left(\phi_{i}^{j}-\bar{\phi}_{i}\right)\left(\phi_{i}^{j}-\bar{\phi}_{i}\right)^{\prime},
$$

where the index $i$ refers to the horizon for which the impulses are calculated; $\phi_{i}^{j}$ is an $n \times n$ matrix of standardised impulses for the $j$ th rotation; and $\bar{\phi}_{i}$ is the median impulse over all possible rotations. ${ }^{17}$ Full details of the methodology and implementation are provided in the Appendix.

\section{Sign-Restricted VAR Results}

The identification scheme based on the signrestricted VAR allows for a structural interpretation of the effects of shocks. The impulse response of the output gap, the interest rate, inflation, the real exchange rate and the terms of trade with respect to the three foreign shocks are shown in Figure 4. An exogenous increase in the foreign interest rate results in a depreciation of the exchange rate which raises domestic inflation. In contrast to the DSGE model, the depreciation of the exchange rate is more gradual, reaching a peak at eight quarters before returning to equilibrium. A more important difference from the DSGE results is that output falls, which appears to reflect the decline in foreign output (not shown) and would also help to explain why domestic interest rates decline.

In contrast to the DSGE estimates, the signrestricted VAR estimates imply that an increase in foreign output leads to a positive domestic output gap, reaching a peak after four quarters. The positive domestic output gap implies increased inflationary pressure, which induces a tightening of monetary policy over time to bring both output and inflation back to steady state. The response of the domestic economy following a foreign inflation shock is very similar to that implied by the DSGE model. The exchange rate appreciates in response to the lower real interest rate differential. This leads to a fall in the output gap and subsequently a decline in inflation. There is a small monetary loosening to bring both output and inflation back to equilibrium.

Figures 4 and 5 display the summary IRFs from the sign-restricted VAR for the remaining five domestic shocks. A positive output shock (i.e. a negative technology shock) raises the

\footnotetext{
${ }^{17}$ In Fry and Pagan (2005), $q$ is set to 1 focusing only on the initial period impulse.
}

interest rate consistent with the sign restriction. This shock also induces inflationary pressure and the interest rate remains above its steadystate level for some time. An unanticipated tightening of monetary policy lowers both inflation and output whereas the exchange rate appreciates in response to higher real interest rates. After the shock, the interest rate falls so as to stimulate output and bring inflation back to its steady-state level. Following a positive cost-push shock, the domestic interest rate increases, the exchange rate appreciates and the output gap falls. A negative shock to the risk premium triggers an appreciation of the exchange rate leading to lower inflation. The monetary authority responds to this by lowering the domestic interest rate. In contrast to the structural model, the effect of the monetary response is estimated to outweigh the effect of the higher exchange rate, leading to higher output. A terms of trade shock has a positive effect on both output and inflation leading to a tightening of monetary policy. The exchange rate also responds to the higher terms of trade, helping to stabilise both output and inflation.

The results highlight important differences between the responses of the SRVAR compared with the estimated DSGE model. This further emphasises Del Negro and Schorfheide's (2009) conclusion that model mis-specification remains the key challenge in applied macroeconomic research. However, this is not to say that all the restrictions are invalid; some remain useful especially when the data cannot be used to help distinguish competing theories as in the case of exactly identified VARs. Peersman and Straub (2009) use a similar approach to try and disentangle the response of hours worked following a productivity shock in the euro area.

\section{(i) Main Drivers of Output Over the Business Cycle}

Variance decompositions are often used to determine the relative contribution of shocks to the forecast error variance of a variable of interest over different horizons. As a benchmark, I first present a variance decomposition based on the Choleski decomposition. The variables are ordered according to the convention that the most exogenous (or predetermined) variables appear first. The variance decomposition results reported in Table 4 are based on the following ordering: foreign output, foreign inflation, the foreign interest rate, the terms of trade, the 


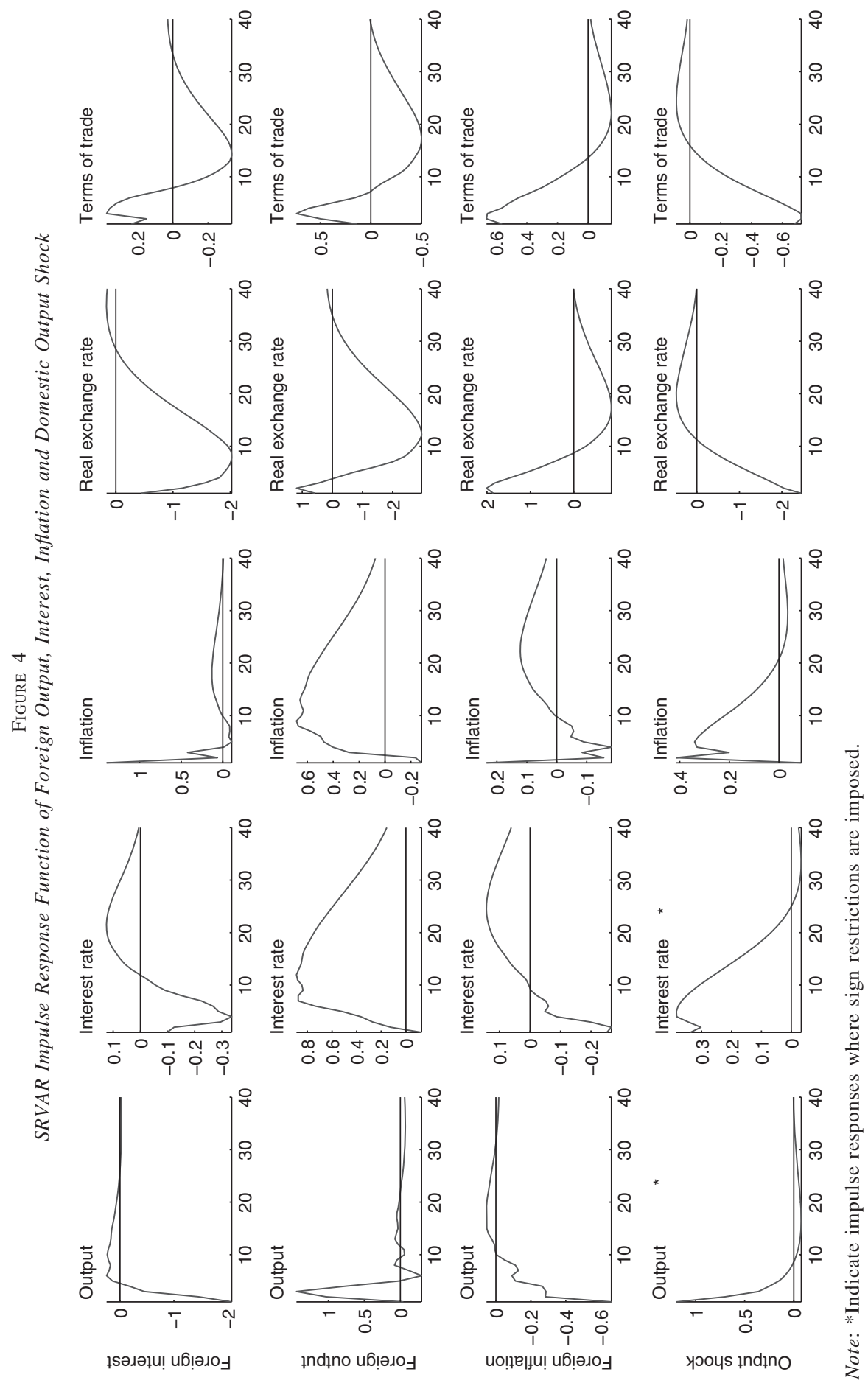




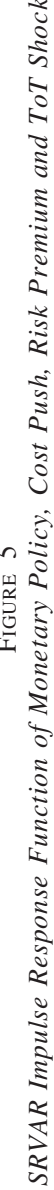
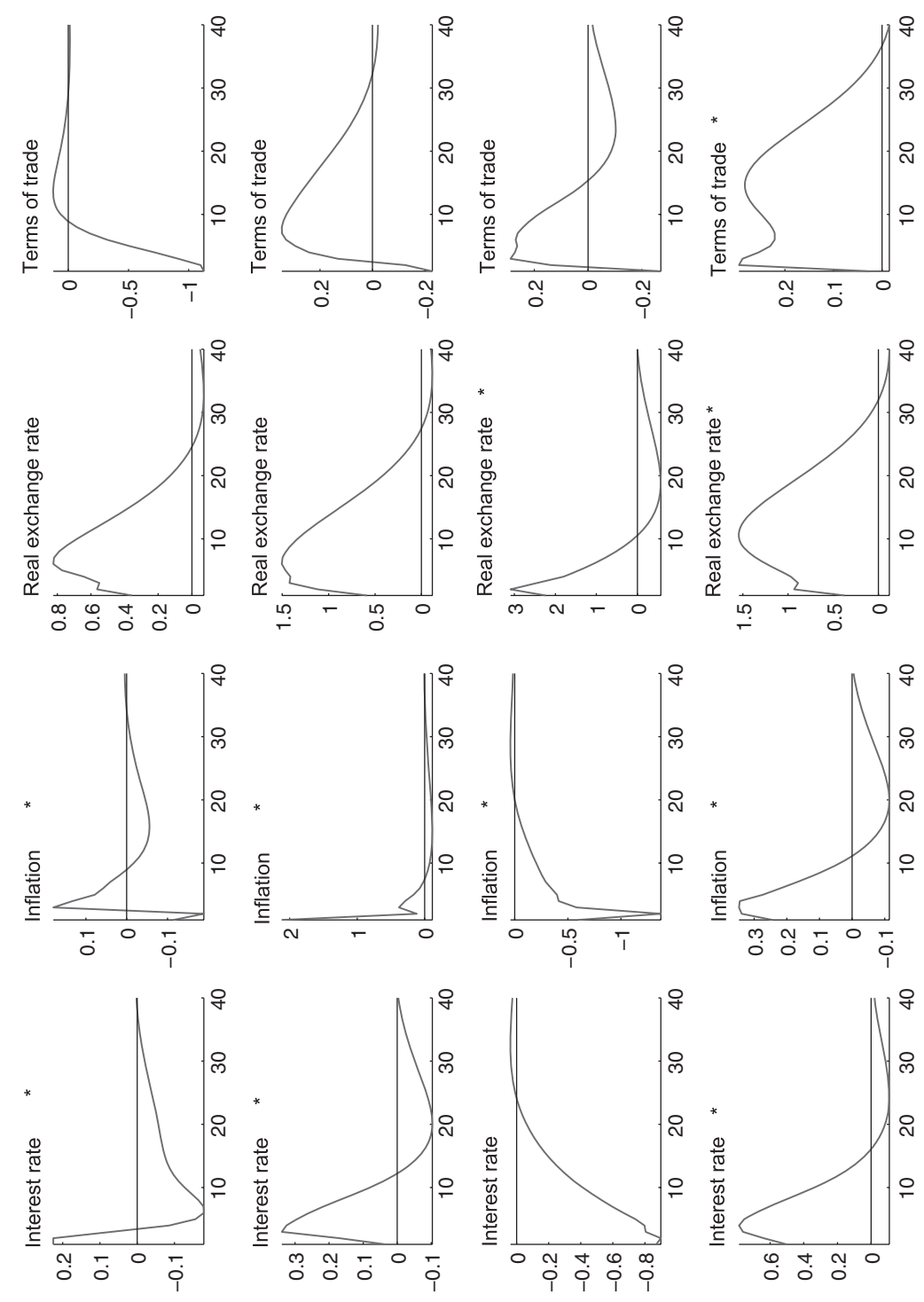

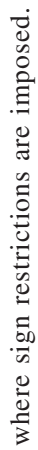
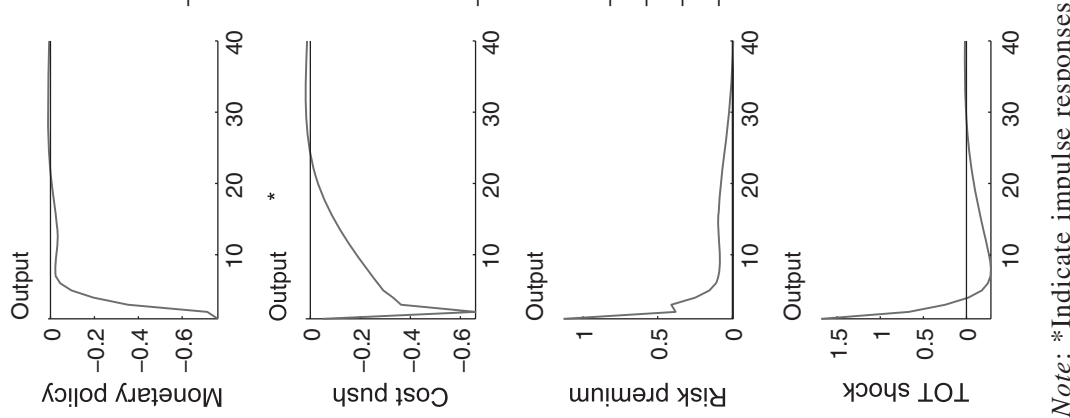

(C) 2010 The Economic Society of Australia 
TABLE 4

Baseline Choleski Variance Decomposition of Output, Interest, Inflation and Real Exchange Rate

\begin{tabular}{|c|c|c|c|c|c|c|c|c|}
\hline Horizon & $\begin{array}{l}\text { Foreign } \\
\text { interest }\end{array}$ & $\begin{array}{c}\text { Foreign } \\
\text { output }\end{array}$ & $\begin{array}{l}\text { Foreign } \\
\text { inflation }\end{array}$ & Output & Interest & $\begin{array}{l}\text { Cost } \\
\text { push }\end{array}$ & $\begin{array}{l}\text { Exchange } \\
\text { rate }\end{array}$ & ToT \\
\hline \multicolumn{9}{|l|}{ Output } \\
\hline 1 & 0.3 & 2.0 & 7.5 & 89.0 & 0.0 & 0.0 & 0.0 & 1.2 \\
\hline 4 & 3.3 & 15.7 & 7.5 & 65.8 & 0.9 & 3.5 & 2.3 & 1.0 \\
\hline 8 & 3.1 & 14.8 & 8.9 & 62.1 & 1.9 & 4.5 & 3.3 & 1.4 \\
\hline 12 & 3.0 & 14.5 & 9.1 & 60.1 & 2.8 & 5.3 & 3.7 & 1.5 \\
\hline 50 & 3.0 & 14.4 & 9.1 & 58.6 & 3.8 & 5.8 & 3.8 & 1.6 \\
\hline \multicolumn{9}{|c|}{ Interest rate } \\
\hline 1 & 0.7 & 0.1 & 1.2 & 3.7 & 90.5 & 1.6 & 0.0 & 2.1 \\
\hline 4 & 1.9 & 9.8 & 5.3 & 17.2 & 53.7 & 10.8 & 0.7 & 0.7 \\
\hline 8 & 5.1 & 16.7 & 4.5 & 24.9 & 35.7 & 12.3 & 0.3 & 0.4 \\
\hline 12 & 6.4 & 19.7 & 3.7 & 28.4 & 29.2 & 11.5 & 0.4 & 0.7 \\
\hline 50 & 8.9 & 23.0 & 2.9 & 29.1 & 22.5 & 9.1 & 1.1 & 3.4 \\
\hline \multicolumn{9}{|l|}{ Inflation } \\
\hline 1 & 3.0 & 0.9 & 0.1 & 0.7 & 0.0 & 94.9 & 0.0 & 0.4 \\
\hline 4 & 2.7 & 2.4 & 1.8 & 0.9 & 12.1 & 74.1 & 4.0 & 2.0 \\
\hline 8 & 3.7 & 5.8 & 2.2 & 4.4 & 12.5 & 64.3 & 4.2 & 3.0 \\
\hline 12 & 5.1 & 8.4 & 2.0 & 6.8 & 11.6 & 58.2 & 4.5 & 3.4 \\
\hline 50 & 7.4 & 11.7 & 1.8 & 8.8 & 10.3 & 50.8 & 4.6 & 4.6 \\
\hline \multicolumn{9}{|c|}{ Exchange rate } \\
\hline 1 & 0.7 & 0.1 & 0.0 & 0.1 & 3.0 & 0.0 & 87.8 & 8.2 \\
\hline 4 & 0.7 & 0.1 & 6.8 & 3.2 & 2.8 & 3.9 & 80.5 & 2.1 \\
\hline 8 & 4.5 & 1.2 & 14.3 & 2.2 & 2.8 & 5.3 & 68.0 & 1.7 \\
\hline 12 & 9.3 & 2.8 & 17.6 & 1.7 & 6.5 & 5.3 & 55.1 & 1.7 \\
\hline 50 & 11.7 & 4.0 & 17.0 & 1.8 & 13.5 & 5.4 & 44.6 & 2.0 \\
\hline
\end{tabular}

output gap, inflation, the interest rate and the real exchange rate. Investigation of other ordering schemes, where the order of output among the domestic variables varies from first to last, reveals little difference in the variance decomposition results for output. The benchmark results show that at the 1-year horizon, shocks to the domestic output gap account for around two-thirds of the total variance in the output gap whereas other domestic factors play only a modest role. Foreign shocks account for just over one quarter of the output gap forecast error variance, with the biggest contributor being foreign output accounting for around 16 per cent. At longer horizons, the role of domestic output shocks decreases slightly whereas other domestic factors play a slightly larger role. The contribution from all foreign factors stays fairly constant across the different forecasting horizons.

Looking at the variance decomposition of the shocks identified by the sign-restricted VAR model reveals some important differences (Table 5). These results suggest that domestic output shocks account only for $4-5$ per cent of the variation across all horizons. At the shorter horizons, all three foreign factors combine to account for more than 60 per cent of the output gap forecast error variance. A sizeable share of this appears to be owing to foreign monetary policy innovations, although this may, in part, reflect factors that are outside the model, such as global confidence, which are transmitted to the domestic economy via international financial markets. This view is consistent with the findings in Dungey and Pagan (2000), which shows that international financial linkages are important when modelling the Australian economy. At the longer forecasting horizon, all three foreign factors maintain their influence on domestic output gap variations with both the foreign interest rate and foreign output remaining the dominant contributors. Although the model treats the terms of trade as endogenous, realistically it can be thought of as exogenous, at least over longer horizons. So in this respect the terms of trade could be thought of as another foreign factor. The terms of trade 
TABLE 5

SRVAR Variance Decomposition of Output, Interest, Inflation and Real Exchange Rate

\begin{tabular}{|c|c|c|c|c|c|c|c|c|}
\hline Horizon & $\begin{array}{l}\text { Foreign } \\
\text { interest }\end{array}$ & $\begin{array}{c}\text { Foreign } \\
\text { output }\end{array}$ & $\begin{array}{l}\text { Foreign } \\
\text { inflation }\end{array}$ & Output & Interest & $\begin{array}{l}\text { Cost } \\
\text { push }\end{array}$ & $\begin{array}{l}\text { Exchange } \\
\text { rate }\end{array}$ & ToT \\
\hline \multicolumn{9}{|l|}{ Output } \\
\hline 1 & 49.1 & 0.0 & 1.5 & 5.2 & 0.2 & 0.7 & 7.4 & 35.9 \\
\hline 4 & 41.7 & 17.1 & 1.8 & 4.4 & 0.5 & 5.2 & 4.8 & 24.5 \\
\hline 8 & 40.5 & 17.0 & 1.9 & 4.4 & 0.5 & 6.6 & 4.8 & 24.3 \\
\hline 12 & 40.1 & 16.7 & 1.9 & 4.3 & 0.5 & 7.2 & 4.8 & 24.6 \\
\hline 50 & 39.4 & 16.6 & 2.0 & 4.4 & 0.5 & 7.5 & 5.0 & 24.6 \\
\hline \multicolumn{9}{|c|}{ Interest rate } \\
\hline 1 & 2.4 & 2.2 & 5.6 & 11.1 & 3.1 & 6.6 & 59.4 & 9.5 \\
\hline 4 & 1.8 & 3.7 & 3.6 & 8.1 & 1.4 & 13.7 & 46.4 & 21.2 \\
\hline 8 & 1.6 & 20.3 & 1.9 & 7.3 & 1.4 & 10.3 & 34.4 & 22.6 \\
\hline 12 & 1.3 & 32.5 & 1.5 & 7.2 & 1.4 & 8.0 & 28.9 & 19.2 \\
\hline 50 & 1.1 & 54.7 & 1.6 & 5.2 & 1.0 & 5.5 & 18.6 & 12.3 \\
\hline \multicolumn{9}{|l|}{ Inflation } \\
\hline 1 & 25.7 & 0.8 & 1.2 & 0.1 & 8.2 & 63.1 & 0.5 & 0.4 \\
\hline 4 & 19.6 & 3.1 & 1.6 & 3.7 & 6.0 & 44.2 & 19.8 & 2.1 \\
\hline 8 & 16.2 & 11.9 & 1.7 & 6.1 & 4.9 & 37.2 & 19.2 & 2.8 \\
\hline 12 & 14.1 & 21.4 & 1.5 & 6.5 & 4.3 & 32.3 & 17.5 & 2.5 \\
\hline 50 & 10.8 & 38.9 & 1.8 & 5.1 & 3.3 & 24.6 & 13.2 & 2.3 \\
\hline \multicolumn{9}{|c|}{ Exchange rate } \\
\hline 1 & 0.5 & 2.2 & 23.3 & 43.9 & 2.7 & 1.0 & 26.2 & 0.1 \\
\hline 4 & 8.6 & 3.2 & 18.9 & 27.6 & 3.2 & 6.1 & 30.2 & 2.3 \\
\hline 8 & 13.2 & 11.9 & 12.7 & 20.2 & 4.0 & 12.6 & 21.1 & 4.4 \\
\hline 12 & 13.5 & 25.8 & 8.8 & 13.8 & 3.5 & 14.0 & 14.3 & 6.3 \\
\hline 50 & 10.7 & 40.0 & 7.8 & 9.4 & 2.5 & 11.9 & 10.1 & 7.5 \\
\hline
\end{tabular}

account for a quarter of the variation in output across all but the shortest of horizons. This is consistent with the significance of commodities in Australian exports. Turning to domestic factors, interest rate shocks are estimated to have only a small influence on output gap fluctuations, whereas inflation (cost-push) and exchange rate (risk premium) shocks each contribute around 5-8 per cent to the variance of the output gap. This is broadly similar to the Choleski baseline results.

One may ask what is the role of foreign factors among other admissible rotations as it is impossible to distinguish them statistically. To check the sensitivity of the variance decomposition results around the optimised median impulse, the chosen median rotation is dropped and the next median impulse is found by re-optimising Equation (20) over the remaining admissible rotations. Repeating this procedure 50 times around the 'median region' reveals foreign factors that explain between 45 and 60 per cent of the unconditional variance in output, with foreign interest rates remaining the dominant contributor. To give a more complete
FIGURE 6

SRVAR Variance Decomposition of Foreign versus Domestic Factors Across 2000 Rotations
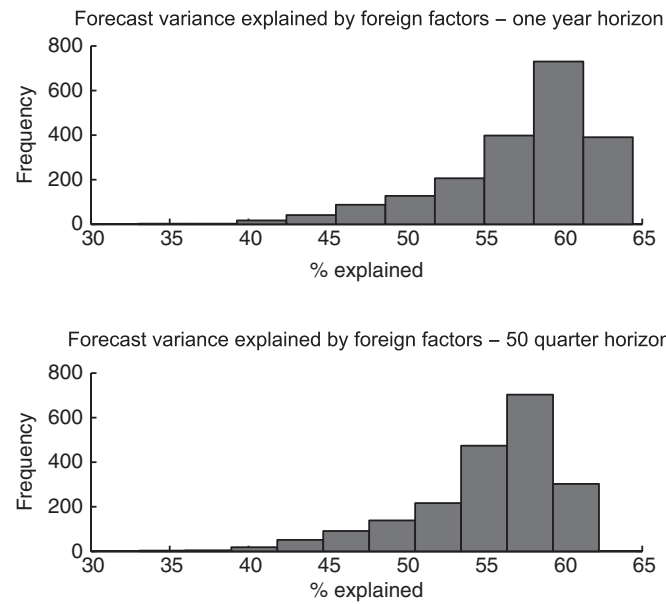

picture, Figure 6 plots the forecast error variance for the output gap attributed to foreign factors at both the 1-year and 50-quarter horizon 
across all 2000 admitted rotations. ${ }^{18}$ The first point to note is that the results presented here lie exactly on the mode of the distribution, whereas the baseline Choleski decomposition lies in the thin tail of the distribution. Looking at the range of values from the sign-restricted VAR analysis, it appears that the true importance of foreign factors may not be easily captured by Choleski decompositions that impose contemporaneous (zero) coefficient constraints. ${ }^{19}$

Variance decompositions may reveal which shocks are important in explaining the forecast errors of output across different horizons. However, Fry and Pagan (2005) argue that they may not be very useful in understanding the nature of business cycle fluctuations. One useful statistic is to decompose the historical observation of output into its MA representation in terms of shocks, that is,

$$
y_{t}=\sum_{j=1}^{k} C_{j}(L) \epsilon_{j, t}+\text { initial condition, }
$$

where $C_{j}(L)$ is the impulse response to the shock $j^{20}$ Historical decompositions are particularly useful in relating certain events that have happened over the business cycle.

Figure 7 plots the historical decomposition of output into foreign (output, inflation and interest rates) versus domestic factors. During the two recessionary periods (the early 1980s and 1990s), both domestic and foreign factors had contributed negatively to output. This observation is consistent with the results reported in Dungey (2002). From the early 1990s onwards, the Australian economy experienced relatively

\footnotetext{
18 The contribution from domestic factors can be easily read off the graphs as the two factors must sum to 100 .

${ }^{19}$ Re-estimating the sign-restricted VAR over the shorter sample 1992:Q1-2006:Q1 suggests that if anything foreign output shocks have become more important for explaining the variance of the domestic output gap, whereas shocks to foreign interest rates have become less so. However, this sample may be too short to produce reliable estimates of the relatively high-dimensional VAR.

${ }^{20}$ As the entire history of shocks are not observed, the decomposed components of $y_{t}$ may not add up exactly for the initial periods of the sample. In the case of output, this is around 6-8 quarters, which are dropped from the decomposition results shown in Figure 6.
}

Figure 7

Historical Decomposition of Output Using US Data

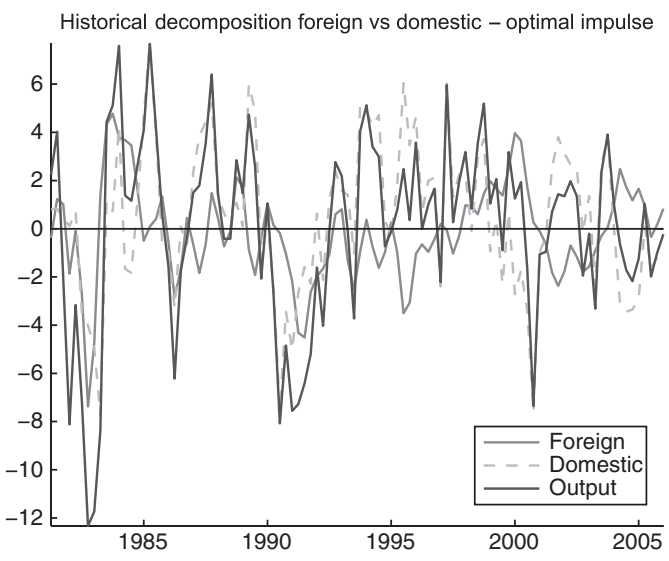

stable and low inflation combined with robust output growth. Coincidentally, foreign and domestic shocks appear to have had offsetting effects so as to moderate domestic business cycle fluctuations during this period. For example, the slowdown in the economy after the Sydney Olympic games together with the introduction of GST in 2000 was somewhat offset by buoyant conditions before the burst of the 'dot-com' bubble in the United States. A buoyant housing market and strong household consumption in the early part of this decade was moderated by a temporary downturn in the US economy following the terrorist attacks in September 2001. The pattern continued in late 2003, where slowing conditions in the Australian housing market were offset somewhat by a relatively strong US economy.

\section{(ii) Robustness Checks}

\section{G7 as the foreign economy}

To check the robustness of these results, the sign-restricted VAR model is re-estimated using G7 data as the foreign economy. It is certainly the case that China has become increasingly more important for the Australian economy, as of 1 October 2009; the RBA calculates the share of the Chinese currency in the trade-weighted index (TWI) to be over 16 per cent. However, over a large part of the sample this article considers, the G7 countries remained as Australia's dominant trading partners. According to 
the RBA Bulletin (2002), the weight of the Chinese currency in Australia's TWI ranged from 2 per cent in 1980 to 8.5 per cent in 2002, whereas the G7 countries accounted for 77 to 52 per cent over the same period.

The overall conclusion using the G7 dataset is supported although minor differences do arise. ${ }^{21}$ The combined contribution of foreign shocks accounts for around 63 per cent of the forecast error variance for the output gap at the 1-year horizon, similar to that reported earlier. At the 50 -quarter horizon, this increases to 76 per cent in contrast to 59 per cent based on using only US data. Consistent with the earlier estimates, innovations from domestic output play a smaller role in explaining domestic output gap forecast errors. However, within the set of international variables, foreign output now takes on a larger role compared with foreign interest rates. This tends to suggest that interest rates may pick up other global factors in the results based on US output alone.

\section{Using the HP filter as alternative detrending method}

Another important assumption behind the aforementioned discussions is that the results are based on cyclical movements extracted from the $\mathrm{BN}$ decomposition. As an additional robustness check, the VAR is re-estimated using cyclical movements extracted from the HP filter.

Across all horizons, the three foreign shocks together contribute around 50 per cent of the forecast errors for output, whereas domestic output shocks only account for under 9 per cent. In contrast to the $\mathrm{BN}$ decomposition, foreign output shocks are now the dominant contributor at around 30 per cent and foreign interest rate shocks around 17 per cent. The results demonstrate that the key determinant of the output forecast error rests with the sign restriction identification.

\section{Conclusion}

This article uses a small open economy VAR model to investigate the sources of business cycle fluctuations for the Australia economy. The VAR is identified using robust sign restrictions derived from an estimated small structural (DSGE) model. The results suggest that inter-

\footnotetext{
${ }^{21}$ Detailed statistics are not reported but are available upon request.
}

national factors account for over half the domestic output fluctuations whereas demand type shocks play a small role. The result appears to be robust to alternative detrending of the data and using different representation as the foreign economy.

This article tries to address some of the shortcomings in the earlier sign restriction literature that the sign restrictions are arbitrarily imposed by selecting a set of robust sign restrictions from an estimated structural model. However, the analysis does not tackle the question as to which model is more valid and this issue is left for future work.

\section{REFERENCES}

An, S. and Schorfheide, F. (2007), 'Bayesian Analysis of DSGE Models', Econometric Reviews, 26, 113-72.

Brischetto, A. and Voss, G. (1999), 'A Structural Vector Autoregression Model of Monetary Policy in Australia', Research Discussion Paper No. 99-11, RBA.

Brooks, S. and Gelman, A. (1998), 'Alternative Methods for Monitoring Convergence of Iterative Simulations', Journal of Computational and Graphical Statistics, 7, 434-55.

Canova, F. (1998), 'Detrending and Business Cycle Facts', Journal of Monetary Economics, 41, 475-512.

Canova, F. and De Nicolo, G. (2002), "Monetary Disturbances Matter for Business Fluctuations in the G-7', Journal of Monetary Economics, 49, 1131-59.

Del Negro, M. and Schorfheide, F. (2009), 'Monetary Policy Analysis with Potentially Misspecified Models', American Economic Review, 99, 1415-50.

Dungey, M. (2002), 'International Shocks and the Role of Domestic Policy in Australia', Australian Journal of Labour Economics, 5, 142-63.

Dungey, M. and Pagan, A. (2000), 'A Structural VAR Model of the Australian Economy', Economic Record, 76, 321-42.

Dungey, M. and Pagan, A. (2009), 'Extending a SVAR Model of the Australian Economy', Economic Record, 85, 1-20.

Farrant, K. and Peersman, G. (2006), 'Is the Exchange Rate a Shock Absorber or a Source of Shocks? New Empirical Evidence', Journal of Money, Credit and Banking, 38, 939-62.

Faust, J. (1998), 'The Robustness of Identified VAR Conclusions about Money', Carnegie-Rochester Conference Series on Public Policy, 49, 207-44.

Fry, R. and Pagan, A. (2005), 'Some Issues in Using VARs for Macroeconometric Research', Working paper No. 2005-18, ANU, Centre for Applied Macroeconomic Analysis Working Papers.

Fukac, M. and Pagan, A. (2006), 'Issues in Adopting DSGE Models for Use in the Policy Process', 
Working Papers No. 2006-10, ANU, Centre for Applied Macroeconomic Analysis.

Gali, J. and Monacelli, T. (2005), 'Monetary Policy and Exchange Rate Volatility in a Small Open Economy', Review of Economic Studies, 72, 707-34.

Gillitzer, C., Kearns, J. and Richards, A. (2005), 'The Australian Business Cycle: A Coincident Indicator Approach', RBA Research Discussion Papers No. 05-07.

Lubik, T. and Schorfheide, F. (2006), 'A Bayesian Look at New Open Economy Macroeconomics', in Gertler, M. and Rogoff, K. (eds), NBER Macroeconomics Annual 2005, Vol. 20. MIT Press, Cambridge, MA; 313-82.

Lubik, T. and Schorfheide, F. (2007), 'Do Central Banks Respond to Exchange Rate Movements? A Structural Investigation', Journal of Monetary Economics, 54, 1069-87.

McKibbin, W.J., Pagan, A.R. and Robertson, J.C. (1998), Some Experiments in Constructing a Hybrid Model for Macroeconomic Analysis', CarnegieRochester Conference Series on Public Policy, 49, 113-42.

Monacelli, T. (2005), 'Monetary Policy in a Low Pass-Through Environment', Journal of Money Credit and Banking, 37, 1047-66.

Newbold, P. (1990), 'Precise and Efficient Computation of the Beveridge-Nelson Decomposition of Economic Time Series', Journal of Monetary Economics, 26, 453-7.

Nimark, K. (2007), 'A Structural Model of Australia as a Small Open Economy', RBA Research Discussion Paper No. 2007-01.

Pagan, A. and Pesaran, M.H. (2008), 'Econometric Analysis of Structural Systems with Permanent and Transitory Shocks', Journal of Economic Dynamics and Control, 32, 3376-95.

Peersman, G. (2005), 'What Caused the Early Millennium Slowdown? Evidence Based on Vector Autoregressions', Journal of Applied Econometrics, 20, 185-207.

Peersman, G. and Straub, R. (2004), 'Technology Shocks and Robust Sign Restrictions in a Euro Area SVAR', Working Paper Series No. 373, ECB.

Peersman, G. and Straub, R. (2009), 'Putting the New Keynesian Model to a Test,' International Economic Review, 50, 727-50.

RBA Bulletin, (2002), 'Developments in the TradeWeighted Index', Working Paper, Reserve Bank of Australia Bulletin.

Uhlig, H. (1995), 'A Toolkit for Analyzing Nonlinear Dynamic Stochastic Models Easily', Discussion Paper No. 101, Federal Reserve Bank of Minneapolis, Institute for Empirical Macroeconomics.
Uhlig, H. (2005), 'What are the Effects of Monetary Policy on Output? Results from an Agnostic Identification Procedure', Journal of Monetary Economics, 52, 381-419.

\section{Appendix: Sign Restriction Algorithm}

Define an $(n \times n)$ orthonormal rotation matrix $Q$ such that:

$$
Q=\prod_{i=1}^{n-1} \prod_{j=i+1}^{n} Q_{i, j}\left(\theta_{i, j}\right),
$$

where

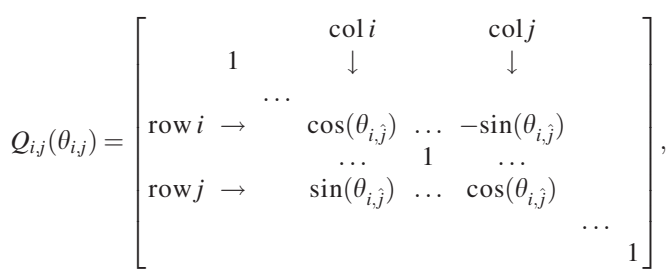

where $\theta_{i, j} \in[0, \pi]$. This provides a way of systematically exploring the space of all VMA representations by searching over the range of values of $\theta_{i, j}$. Although Canova and De Niolo (2002) propose setting up a grid over the range of values for $\theta_{i, j}$, the following algorithm generates the Qs randomly from a uniform distribution:

1. Estimate the VAR in Equation (10) using OLS to obtain the reduced form variance covariance matrix $V$ and compute $\tilde{V}$.

2. Compute the Choleski decomposition of $\tilde{V}_{11}$ and $\tilde{V}_{22}$, where $H_{11}=\operatorname{chol}\left(\tilde{V}_{11}\right)$ and $H_{22}=$ $\operatorname{chol}\left(\tilde{V}_{22}\right)$.

3. For both the foreign and domestic block is, draw a vector of $\theta_{i, j}$ from a Uniform $[0, \pi]$ distribution.

4. Calculate $Q=\prod_{i=1}^{n-1} \prod_{j=i+1}^{n} Q_{i, j}\left(\theta_{i, j}\right)$.

5 . Use the candidate rotation matrix $Q$ to compute $\epsilon_{t}=H Q e_{t}$ and its corresponding structural IRFs $C(L)$ for domestic and foreign shocks.

6. Check whether the IRFs satisfy all the sign restrictions described in Table 3 . If so keep the draw, if not, drop the draw.

7. Repeat steps (3)-(6) until 2000 draws satisfying the restrictions found. 